\title{
Regenerative Medicine Revolution By Personalized Design
}

\section{To Editor,}

\section{The Beginnings}

John A. Catanzaro earned his Doctor of Naturopathic Medicine in 1995 and maintained a clinical integrative practice treating cancer, autoimmune disease, complex diseases and genetic related illnesses for over two decades. Dr. Catanzaro admires pioneers, true revolutionaries in their fields and their work in individualized cancer therapy including William Coley, Glenn Warner, Stan Burzynski, Jonathan Wright, Leigh Erin Connealy and others. He has created a unique model that pioneers a new medical therapy which contemporaries believe to be truly revolutionary. Catanzaro's work with stage 4 cancer patients, who were given up by standard of care, showed a $65 \%$ efficacy even where these patients had been written off as having no cure and hopeless. This set in motion the passing of current legislation, "Right-to-Try" for patients to receive hopeful experimental personalized therapy, further substantiating validity and efficacy of such treatments. However, Catanzaro was forced to retire from clinical practice in 2017 resulting from treatment that was so successful that it gained the attention of the Chief of Seattle Swedish Cancer Institute Breast Cancer Center.

\section{Cancer Free Patient Barred from Treatment}

A triple negative breast cancer patient came to Dr. Catanzaro who had a very large tumor, the size of a melon, growing on a mastectomy site. This was causing the patient to bleed and she needed to have a blood transfusion every three days to stay alive. The patient was being treated by the Chief of Seattle Swedish Breast Cancer Center without having a desired response. This oncologist and her surgical team gave

Significance | Cancer personalized healthcare knowledge letter

${ }^{*}$ Correspondence: John catanzaro at Neo7logix, LLC, 8 Case Mews Gaithersburgh, MD 20878, Maryland, United States of America. Email: john.catanzaro@neo7logix.com, phone: 206718-5467

Edited by Md Shamsuddin Sultan Khan, Western Sydney University, Australia. And accepted by the Editorial Board October 29, 2019 (received for review October 1, 2019) the patient 30 days to live and left her with no hope. She was referred to Dr. Catanzaro and his center and she had a personalized immune vaccine using peptides identified by protein testing isolated from her urine. The identified peptides were manufactured specifically for her and administered as an injection. In three weeks, her tumor broke off in chunks. Then in three months her tumor was gone, her bleeding stopped, and she is presently 8 years cancer free.

This patient had a follow up appointment with her oncologist and surgical team at Swedish and the patient informed them that Dr. Catanzaro's vaccine design evidently cured her disease by showing them saying, while lifting her blouse, "what do you not see?" "You left me for dead." Catanzaro's treatment had saved her life. The Chief of Seattle Swedish Breast Cancer Center reported Catanzaro for treating patients with immune-based approaches that she deemed unethical to Washington State. This made headline news and gained both positive, and harassing, attention. The patient was then told that Catanzaro could not administer any more treatment to her and that he was ordered to cease and desist and discard all patient treatments mandated by the State of Washington Department of Health.

\section{Patients Speak}

Many of Dr. Catanzaro's patients had been treated in cooperation with Seattle Swedish Cancer Institute as Dr. Catanzaro emphasized the importance of combining the best integrative treatment options available. The negative report to Washington State Department of Health came as a surprise. No patients had been harmed, no fatalities, no serious adverse events and patients were alive which otherwise had

\section{Author Affiliation:}

A John Catanzaro, Neo7logix, LLC, 8 Case Mews Gaithersburgh, MD 20878, Maryland, USA

${ }^{\mathrm{B}}$ Andrew Dickens, Dayspring Cancer Clinic, Arizona, USA, email:

info@dayspringcancerclinic.com, phone 480-699-7400 or 855-699-7400.

\section{Please cite this article:}

John Catanzaro, Andrew Dickens, (2019). Regenerative Medicine Revolution By Personalized Design. Biosciences, 1(1), 007-009. 
no hope. Patients were outraged and bombarded Washington State Department of Health with letters and interviews by news agencies stating that these actions were a crime against humanity. They shared their own success stories and demanded Catanzaro's reinstatement and the right for patients to receive life-saving treatments. Dr. Catanzaro's patients reported tumor regression and curative response with increased quality of health. There are patients now living 10 years out with no recurrence of their disease.

\section{Catanzaro Is Not A Novice}

Catanzaro is highly regarded in the integrative medicine community. He was affiliate / adjunct faculty for Bastyr University and taught integrative cancer outpatient medicine to medical students and resident physicians for 15 years. He served on Bastyr Institutional Review Board for 6 years. He was appointed by the Governor and served Washington Department of Health Quality Assurance Board for Naturopathic Medicine for five years as Co-Chair. He also served on the CDC Medical Board Cancer Commission representing Washington State for two years as a medical advisor on integrative cancer care. Dr. Catanzaro also was a former member of the American Association for Cancer Research (AACR).

\section{More Than 500 Patients}

Catanzaro treated more than 500 patients with this personalized immune-based vaccine therapy safely and effectively. He has designed a novel strategy in precision profiling individual patient data transforming it into a personalized therapy design matched specifically to the patient's own immune capability and specific to the disease diagnosis. He developed a team of molecular scientists at Harvard and associated laboratories of Dana Farber Cancer Institute to achieve this novel immune design.

\section{Persistence Downstream}

Early in 2019 Catanzaro was approached by Anton Yuryev, a brilliant Johns Hopkins $\mathrm{PhD}$ in molecular biological sciences. Dr. Yuryev urged Dr. Catanzaro to consider working together to integrate his design with a biological analytics platform that Yuryev along with Elsevier scientists developed to map out molecular biological pathways. These pathways are associated with patient's own genetic and proteomic data specific to disease patterns observed in that specific patient. Catanzaro and Yuryev are now masterminding the movement.

\section{Neo7Logix Precision in Regenerative Design}

Catanzaro and Yuryev, co-founders of Neo7Logix, a precision medicine bio intelligence company, are emerging to revolutionize integrative and regenerative health care in connection with regenerative medicine practitioners globally through personalization for cancer, autoimmune, neurodegenerative and complex diseases by focusing upon the individual patient's unique needs. Regenerative medicine practitioners are indeed the true revolutionaries of healthcare. Catanzaro and Yuryev's commitment to the community is to power up their abilities and offer this hopeful, accessible and expandable design to their patients now.

\section{It's Not a Drug It's the Patient}

In Catanzaro's own words, "we are not focusing on creating a new drug for a disease that the patient encounters, rather we are focusing on the patient's own ability to fight, regulate and adapt against the disease they are experiencing." In other words, they find the underlying immune based molecular faults and design an Immune editing design fix using the patient's own data identifying genetic related protein products called immunopeptide sequences (neoantigens) to initiate immune defense, regulation and adaptation against their disease.

\section{Collaborative Partners and Subsidiaries}

This indeed is regenerative medicine revolutionized at the core and is attracting the attention of physicians and practitioners globally. Dr. Andrew Dickens of Dayspring Cancer Clinic in Scottsdale Arizona, with a practice based on a focus of regenerative / personalized medicine, has joined Neo7Logix. He is partnering with this design in Arizona and interacting with other colleagues nationally and globally. Other nationally known physicians are also inquiring and engaging with Neo7Logix.

Dr. Kaushik Deb, founder, technopreneur and CEO of DiponEd Biointelligence is partnering with Neo7Logix and is forming Neo7 Biointelligence of India. A subsidiary located in Bangalore. Kaushik has several medical centers and patients ready to receive the design. Neo7Logix has other subsidiary interests in China, Russia and Mexico.

\section{PBIMA; A Personalized Regenerative Design}

Personalized regenerative therapy is a simple process that individualizes the patient's treatment to program their immune system to fight and regulate against disease. The design is an individualized immune based system called PBIMA. PBIMA is Precision-Based Immuno-Molecular Augmentation, which simply gathers an individual's data including genetic and proteins expressed in an individual's cells and body tissues. Then performs a precision analysis that initiates a curative fix against the disease or disorder. It's a four-step process that includes testing and data gathering, precision mapping and selection, synthesis and manufacturing of a person's individual immune sequences and finally administration of the therapy in the form of injection for a 20-day period repeated in four cycles over 18 months. The objective is to achieve a curative response within 18 months with the person improving remarkably over that time frame. The treatment design takes approximately 8-10 weeks to complete with an affordable price structure for a personalized therapy. It is offered to the individual patient's treating physician or qualified health care practitioner.

PBIMA, in comparison to other conventional immunotherapies like CAR-T, has no serious side effects because it only uses what is unique to the patient. Patient $\mathrm{A}$ is different than Patient $\mathrm{B}$ and the two are unique. Patient A's treatment cannot be used for Patient B and vice 
versa. It's not about treating the disease, it is about finding the unique solution for the individual patient to defend and regulate against disease. This is not a "one fits all," it is a unique design for a unique individual. It's not creating a drug for the general public, it's creating a solution for the individual using a unique design that custom fits that individual.

\section{Conclusion}

Regenerative physicians and practitioners are true revolutionaries for the advancement of medicine and healthcare. In fact, the FDA has a designation called RMAT Regenerative Medicine Advanced Therapy designation (https://www.fda.gov/vaccines-blood-biologics/cellulargene-therapy-products/regenerative-medicine-advanced-therapydesignation) in order to expedite the hopeful advances as described in this article. Precision and personalization are pivotal in creating diverse, novel approaches unique to the patient in an expanding adaptation against disease. As Dr. Catanzaro so succinctly states, "the focus on the individual patient is key. It's not about discovering a new drug for the disease, it's about creating the unique solution for the patient."

Sincerely,

Dr. Catanzaro, and Dr. Andrew

\section{Author Contribution}

Dr. Catanzaro, and Dr. Andrew Dickens worked for the development of revolutionary changes in healthcare.

\section{Acknowledgment}

Authors would like to acknowledge Neo7Logix for the support.

\section{Competing financial interests}

The author(s) declare no competing financial interests.

\section{References}

No References are mentioned.

Submit your next manuscript to Biosciences

published by Eman Research Ltd

- Convenient online submission

- $\quad$ Thorough peer review

- No space constraints or color figure charges

- Immediate publication on acceptance

- Inclusion in Australian National Libraray and Google Schola

- Both Open (80-100\% subsidized APC by ER) \& non-open access option

Submit your manuscript at

https://publishing.emanresearch.org 